\title{
Intransitividade Cindida no Canela
}

\author{
Splity Intransitivity in Canela \\ Murilo da Silva BARROS* \\ Universidade de Brasília (UnB) \\ Flávia de CASTRO ALVES** \\ Universidade de Brasília (UnB)
}

\begin{abstract}
RESUMO: O artigo apresenta uma pesquisa realizada com traços semânticos de verbos intransitivos e descritivos da língua Canela (Timbira, Jê, Macro-Jê). Essa pesquisa guiou-se pelos conjuntos de traços semânticos postulados por Mithun (1991, 2008). A pesquisa apresentada teve como principal objetivo discutir a possível relação entre traços semânticos e a intransitividade cindida na língua. Para isso, separamos as etapas de pesquisa da seguinte maneira: primeiro, uma breve discussão sobre o alinhamento de intransitividade cindida; depois, uma sistematização das propriedades verbais da classe de descritivos no Canela; e, por último, a análise dos resultados alcançados com a separação de verbos por traços semânticos na língua. Por fim, evidenciamos que a codificação de argumentos de verbos monovalentes na língua opera de acordo com a presença/ausência dos seguintes traços: [performance/efeito/instigação] e [controle].
\end{abstract}

PALAVRAS-CHAVE: Intransitividade Cindida. Canela. Alinhamento Morfossintático.

\begin{abstract}
This article aims to discuss the relation between semantic motivation and split intransitivity in Canela language (Timbira, Jê, Macro-Jê) For this purpose, we clustered intransitive and descriptive verbs in semantic features proposed by Mithun (1991). The results suggest that intransitive verbs have the feature [event] and [Performance/Effect/Instigation], while descriptives are marked with the features [event], [performance/effect/instigation] and [control]. Therefore, one can assume that split intransitivity in those languages are motivated by the semantics implied. We concluded that the morphosyntactic split accompanies a semantic split. In the end, we find that intransitive verbs in the Canela language grammar depend on the absence or presence of the following features: [performance/effect/instigation] and [control].
\end{abstract}

KEYWORDS: Split Intransitivity. Canela. Morphosyntactic Alignment.

\footnotetext{
* Doutorando na Universidade de Brasília. E-mail para contato: murilo.dasilvabarros@gmail.com

** Professora Associada II na Universidade de Brasília. E-mail para contato: flaviacastro@unb.br
} 


\title{
Introdução
}

É de conhecimento geral que estudos tipológicos em relações gramaticais apontam uma cisão na categoria de verbos intransitivos em inúmeras línguas no mundo. Trabalhos como os realizados por Klimov (1974), Perlmutter (1978), Dixon (1994), Creissels (2008), entre outros, mostram uma nítida subdivisão de intransitivos, na qual, ao menos, uma propriedade gramatical distingue itens dessa classe.

Creissels (2008) indica várias possibilidades de distinções gramaticais dentro da classe de intransitivos em línguas não-relacionadas geneticamente - desde propriedades como a marcação de caso, concordância verbal, ordem dos constituintes, até processos gramaticais como nominalização, passivização (Rice, 1991) e assim por diante.

Em línguas Jê Setentrionais como, por exemplo, o Canela ${ }^{1}$, há duas classes de verbos monovalentes: intransitivos e descritivos (Castro Alves, 2004). A seguir, veremos brevemente como seria a cisão intransitiva presente na língua Canela.

Os verbos monovalentes do Canela possuem distintas séries de pronomes na codificação de seus argumentos. Desse modo, argumentos de um grupo de verbos (os denominados intransitivos) são codificados externamente ao sintagma verbal e, quando pronominais, possuem forma morfológica livre (1a) e (1b):

\section{Intransitivos $\left(\mathbf{S a}^{2}\right)$}

$\begin{array}{lll}\text { (1) a. } w \boldsymbol{a} m \tilde{o}^{3} & \text { (1) b. } \boldsymbol{c a} \quad x w a\end{array}$

1 ir $\quad 2$ banhar

"Eu vou" (PDN)

"Você banha" (PDN)

\begin{abstract}
${ }^{1}$ Canela é nome popular de dois grupos Timbira (Apãniekrá e Ramkokamekrá), que vivem em duas terras indígenas próximas ao município de Barra do Corda (MA). Segundo dados do Siasi/Sesai (2012) habitam na região cerca de 3.151 pessoas. A língua falada por esses grupos faz parte da família Jê (Macro-Jê).

${ }^{2}$ Os rótulos Sa e So dizem respeito, respectivamente, ao argumento único de verbos intransitivos, que mais se assemelha com o agente (Sa), e com o paciente (So). Estes rótulos foram elaborados por tipólogos como, por exemplo, Dixon (1994), Bickel (2014), entre outros. A sigla PDN, por sua vez, diz respeito ao projeto "Documentação de Narrativas e Elaboração de Dicionário Canela", coordenado por Castro Alves (UnB). Por fim, As seguintes siglas presentes nas glosas e seus significados: pr (prefixo relacional), nmz (nominalizador), prg (progressivo), erg (ergativo), caus (causativo), nf (não-finito), incl (inclusivo), e irr (irrealis).
\end{abstract}

${ }^{3}$ A grafia presente neste artigo foi desenvolvida, primeiramente, por missionários do Summer Institute of Linguistics (SIL) junto à comunidade Ramkokamekrá e, desde então, vem sendo revista e reformulada pelos professores Canela. Os símbolos seguem, majoritariamente, os símbolos do International Phonetics Alphabet (IPA) Cabe lembrar, todavia, que alguns deles possuem a seguinte correspondência fonológica: e [ع], ê [e], à [3], ỳ [ə], y [i] , ã [ã], o [o], ô [o], c/qu [k], k [kh], g [ng], h em final de sílaba [?], x [t']. 
Argumentos do outro grupo de verbos (os denominados descritivos), diferentemente, são codificados internamente ao sintagma verbal e, quando pronominais, possuem forma morfológica dependente (2a) e (2b). Cabe dizer que essa distinção de codificação pronominal não ocorre em todos os contextos morfossintáticos da língua (Castro Alves, 2010):

\section{Descritivos (So)}

(2) a. $\quad i=j \tilde{o x} w a$

$$
1=\text { estar.com.sono }
$$

"Eu estou com sono" (PDN)
(2) b. $\quad \boldsymbol{a}=c a t \tilde{o} c$

$$
2=\text { estourar }
$$

"Você estoura" (PDN)

Os exemplos acima mostram uma divisão entre intransitivos e descritivos no que toca à codificação de pronomes pessoais. Esses dois tipos de monovalentes, porém, apresentam semelhanças cruciais que os categorizam na mesma classe de palavras: verbos.

Castro Alves (2010) demonstrou que no Canela os argumentos de alguns verbos monovalentes parecerem estar categorizados como agentes transitivos e argumentos de outros como pacientes transitivos. A autora também destaca que o verbo intransitivo parece classificado de acordo com o nível de agentividade do argumento sujeito. Esse é justamente o ponto que precisa ser melhor compreendido e que, por esse motivo, será abordado neste trabalho.

Nas próximas seções, discutiremos as propriedades que aproximam os descritivos a intransitivos e, depois, sistematizamos os verbos intransitivos e descritivos do Canela pelos conjuntos de traços semânticos presentes em Mithun (1991) a fim de realizar uma análise com mais detalhes sobre o possível traço semântico preponderante para uma cisão intransitiva na língua.

\section{Morfossintaxe dos verbos monovalentes}

Castro Alves (2004, p. 57) mostra que "os verbos em Apãniekrá, e somente a eles, estão associadas categorias de tempo, aspecto, modo". Processos sintáticos como, por exemplo, o tempo, o aspecto e o modo, além de operações de mudança de valência e nominalização fazem parte da categoria lexical de verbos na língua. Essas propriedades 
morfossintáticas distributivas são encontradas em verbos descritivos e intransitivos no Canela (Castro Alves, 2010).

Os exemplos abaixo mostram que os descritivos podem ser transitivizados/causativizados (Castro Alves, 2014) (3), podem ocorrer no modo imperativo (6) e podem ocorrer com auxiliares e partículas de aspecto como, respectivamente, o to $=m \tilde{o}$ (8) е о ари (10), assim como nos verbos (4), (5) (7) e (9):

\section{Intransitivo}

(3) to=a=kõn

TRANS $=2=$ beber.NF

“você bebeu” (adaptado de Castro Alves, 2004, p.75)

\section{Descritivo}

(4) cô to $=\mathrm{ih}=$ cacro

água $\quad$ CAUS $=3=$ ser.quente

“ele esquentou a água” (idem, 2004, p.74)

\section{Intransitivo}

(5) gõ

dormir

“durma!" (PDN)
Descritivo

(6) $\quad a=$ pej

$2=$ ser.bom

“seja bom!"” (idem)

\section{Intransitivo}

(7)
cormã
i-pi-kãn
to $=m \tilde{o}$
ainda
3-derreter $\quad$ POSP=ir
“ainda está derretendo (a manteiga)" (adaptado de Castro Alves, 2009, p.8) 


\section{Descritivo}

(8) ih=ncrỳ to=mõ

$3=$ secar $\quad$ POSP $=\mathbf{i r}$

“ele está secando" (adaptado de Castro Alves, 2009, p.9)

\section{Intransitivo}

(9) wa apu apà

$1 \quad$ PRG comer

“eu estou comendo" (idem)

\section{Descritivo}

(10) wa apu i=hêj
$1 \quad$ PRG $1=$ mentir
"eu estou mentindo" (PDN)

Percebemos até agora que certas propriedades morfossintáticas (categorias de tempo, aspecto, modo e operações de mudança de valência) aproximam verbos e descritivos em maior medida do que os morfológicos.

Outra propriedade comum a intransitivos e descritivos é a nominalização. Ela também pode ser acrescentada como um processo morfológico de derivação. Nela, há o acréscimo do morfema nominalizador $=x a ̀$ acontece com verbos como $x$ wỳr 'banhar' e descritivos como pec 'estar cansado'. É importante mencionar que esse morfema não ocorre nos nomes.

\section{Intransitivo}

(11) $\mathrm{i}=\mathrm{xwỳr}=\mathbf{x a ̀}$

$1=$ banhar.NF=NMZ

“o meu banho" (Castro Alves, 2004, p.54)

\section{Descritivo}

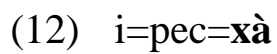

$1=$ ser.cansado $=\mathbf{N M Z}$

“ser preguiçoso" (PDN) 
Outra similaridade entre verbos e descritivos é a ocorrência do modo irrealis (13), (14). Antecipadamente, alertamos que em algumas construções específicas, no entanto, o morfema de modo irrealis ha ocorre em orações nominais.

\section{Intransitivo}

$(13)$

$$
\begin{array}{lll}
\text { quê } & \text { ha } & \text { pôj } \\
3 & \text { IRR } & \text { chegar } \\
& & \\
\text { “ele vai chegar" (PDN) }
\end{array}
$$

\section{Descritivo}

$$
\begin{aligned}
& \text { cu ha } \quad \text { pah=cacro } \\
& \text { 1.INCL IRR } 1 . \text { INCL=ser.quente } \\
& \text { "nós vamos ficar com febre" (PDN) }
\end{aligned}
$$

No que se refere a propriedades nominais comuns a descritivos e nomes, podemos citar os morfemas intensificadores que ocorrem na língua. Entre eles, o diminutivo = re e o aumentativo $=t i$ são sufixos intensificadores que podem ser empregados tanto em nomes (15), como em descritivos (16):
(15) $\quad$ rop=ti
(16) ajo=re
cachorro=AUM
ser.redondo=DIM
“onça" (PDN)
"ser redondinho" (idem)

No que se refere aos estudos sobre monovalentes no Canela, é importante mencionar a variação morfológica na raiz verbal existente nessa classe. Grupp (2015, p. 19-23) verificou que a língua possui, ao menos, cinco diferentes possibilidades de mudanças irregulares em verbos com a forma não-finita utilizada para o passado. Isso pode ser evidenciado nos exemplos a seguir:
akru

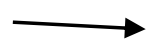
hàkrun
dançar
dançar.NF
“dança” (Grupp, 2015, p.19)
“dançou" (idem) 
(18)

(19)

(21)

$$
\begin{aligned}
& \text { acxa } \longrightarrow \text { ipixar } \\
& \text { rir rir.NF } \\
& \text { "ri” (idem) "riu” (idem) }
\end{aligned}
$$

\section{pixar}

ijàhcukren/hàhcukren

correr.NF (com tora)

"correu" (idem)

jàkjer/hàkjer

chamar.NF

"chamou" (idem)

j/hũcana

suportar.NF

"suportou" (idem)

Podemos ver, com os exemplos acima, que raízes intransitivos em sua forma nãofinita podem variar de cinco maneiras distintas: a/hà; ah/jà- ou ah/hà-; ø-/jà- ou ø-/hà-; aw/jũ- ou aw-/hũ- e ac-/(i)pi-. Essa é uma propriedade morfológica importante em intransitivos e pode ser observada nos exemplos de verbos intransitivos apresentados neste artigo nas próximas seções.

Castro Alves (2010) descreve também duas propriedades morfológicas comuns a nomes, descritivos e verbos na língua: os prefixos relacionais (22), (23) e (24) e os prefixos pessoais (25), (26) e (27), conforme podemos observar nos exemplos a seguir:

\section{Nome}

(22)

$$
\mathrm{a}=\mathbf{j} \text {-arkwa }
$$

$2=$ PR-boca

"sua boca" (PDN)

\section{Descritivo}

(23) $\mathbf{x}$-àr

PR-ser.cozido

“estar cozido" (idem)

\section{Intransitivo}

(24) $\quad \mathbf{x}$-wa

PR-banhar

"banhar" (idem) 
Nome

Descritivo

Intransitivo

(25)

$\mathrm{ih}=\mathrm{krã}$

(26)

$a=$ carẽj

(27) $\quad \mathrm{i}=\mathrm{tu}$

$3=$ cabeça

$2=$ gritar

$1=$ urinar

"cabeça dele" (idem)

"você grita" (idem)

“eu urino" (idem)

O quadro abaixo (Barros, 2019) sintetiza as propriedades compartilhadas entre as três classes (nomes, verbos e descritivos) em Canela. Propriedades estas também relatadas em outras línguas Jê Setentrionais (ver Oliveira, 2005) Como se verifica, a similaridade entre descritivos e intransitivos é evidente quando propriedades distributivas são verificadas:

Quadro 1 - critérios morfossintáticos para classes de palavras no Canela

\begin{tabular}{|l|c|c|c|}
\hline & Verbos & Descritivos & Nomes \\
\hline intensificadores $=$ re/ti & - & $\mathrm{X}$ & $\mathrm{X}$ \\
\hline prefixo pessoal & $\mathrm{X}$ & $\mathrm{X}$ & $\mathrm{X}$ \\
\hline prefixo relacional & $\mathrm{X}$ & $\mathrm{X}$ & $\mathrm{X}$ \\
\hline modo irrealis & $\mathrm{X}$ & $\mathrm{X}$ & $\mathrm{X}$ \\
\hline forma não-finita & $\mathrm{X}$ & $\mathrm{X}$ (restrito) & - \\
\hline nominalizador $=\boldsymbol{x} \grave{a}$ & $\mathrm{X}$ & $\mathrm{X}$ & - \\
\hline modo imperativo & $\mathrm{X}$ & $\mathrm{X}$ & - \\
\hline causativização & $\mathrm{X}$ & $\mathrm{X}$ & - \\
\hline aspecto progressivo & $\mathrm{X}$ & $\mathrm{X}$ & - \\
\hline
\end{tabular}

Depois de revisarmos as evidências para a existência de uma classe de descritivos na língua nos trabalhos de Castro Alves (2004, 2010), pesquisamos possíveis diferenças semânticas entre esses dois grupos de monovalentes a partir de um levantamento quantitativo, o qual será apresentado na próxima seção.

\section{Motivações semânticas para a Intransitividade Cindida}

Mithun (1991, 2008) realizou um estudo tipológico com traços semânticos que condicionam a cisão intransitiva nas línguas Lakhota, Guaraní e o Pomo Central. A pesquisa 
mostrou que traços, como [evento], [performance, efeito e instigação] (P/E/I), [controle] e [afetação], são cruciais na codificação de argumentos intransitivos (Sa e So) nessas línguas. A síntese de sua pesquisa está resumida a seguir:

Quadro 2 - Sumário traços semânticos e línguas relacionadas

\begin{tabular}{|c|c|c|c|}
\hline & Guaraní & Lakhota & $\begin{array}{c}\text { Pomo } \\
\text { Central }\end{array}$ \\
\hline$[+$ evento, +P/E/I, +controle] & Sa & Sa & So \\
\hline [+evento, +P/E/I, -controle] & Sa & $\mathbf{S a}$ & So \\
\hline [+evento, -P/E/I, -controle] & Sa & So & So \\
\hline$[$-evento, +P/E/I, +controle $]$ & So & $\mathbf{S a}$ & Sa \\
\hline [-evento, -P/E/I, -controle, -afetação] & So & So & $\mathbf{S a}$ \\
\hline [-evento, -P/E/I -controle, +afetação] & So & So & So \\
\hline
\end{tabular}

Fonte: Mithun, 1991, p. 524

A autora definiu, portanto, que diferentes propriedades gramaticais dentro da classe de intransitivos nessas línguas são orientadas por conjunto de traços semânticos gerais. Cabe lembrar que não negligenciamos, porém, as possíveis influências culturais nas concepções semânticas verbais que podem haver de cultura para cultura. Em um estudo comparativo, no entanto, faz-se possível verificar uma tendência de grupo de verbos a possuírem traços próprios que guiam uma sistematização como a proposta por Mithun (1991). Abaixo, separamos alguns exemplos de verbos que possuiriam esses grupos de traços semânticos a fim de definir o que entendemos que denotaria cada conjunto de traço semântico:

Quadro 3 - exemplos de verbos com os conjuntos de traços semânticos

\begin{tabular}{|c|c|c|c|c|c|}
\hline 1 & 2 & 3 & 4 & 5 & 6 \\
\hline $\begin{array}{l}\text { +evento } \\
+\mathrm{P} / \mathrm{E} / \mathrm{I} \\
+ \text { controle }\end{array}$ & $\begin{array}{l}\text { +evento } \\
+\mathrm{P} / \mathrm{E} / \mathrm{I} \\
\text {-controle }\end{array}$ & $\begin{array}{l}\text { +evento } \\
\text {-P/E/I } \\
\text {-controle }\end{array}$ & $\begin{array}{l}\text {-evento } \\
+\mathrm{P} / \mathrm{E} / \mathrm{I} \\
+ \text { controle }\end{array}$ & $\begin{array}{l}\text {-evento } \\
\text {-P/E/I } \\
\text {-controle } \\
\text {-afetação }\end{array}$ & $\begin{array}{l}\text {-evento } \\
\text {-P/E/I } \\
\text {-controle } \\
\text { +afetação }\end{array}$ \\
\hline $\begin{array}{l}\text { correr } \\
\text { pular } \\
\text { ir }\end{array}$ & $\begin{array}{l}\text { espirrar } \\
\text { soluçar } \\
\text { vomitar }\end{array}$ & $\begin{array}{l}\text { cair } \\
\text { morrer } \\
\text { deslizar }\end{array}$ & $\begin{array}{l}\text { residir } \\
\text { ser paciente } \\
\text { ser } \\
\text { prudente }\end{array}$ & $\begin{array}{l}\text { ser alto } \\
\text { ser forte } \\
\text { ser destro }\end{array}$ & $\begin{array}{l}\text { estar frio } \\
\text { estar } \\
\text { doente } \\
\text { estar } \\
\text { cansado }\end{array}$ \\
\hline
\end{tabular}


Agora investigaremos qual motivação semântica poderia haver para a existência de duas classes de verbos monovalentes com codificações pronominais distintas em Canela. Para isso, separamos os verbos intransitivos (2.1) e descritivos (2.2), presentes nos trabalhos descritivos sobre a língua (Popjes; Popjes, 1986; Castro Alves, 1999, 2004, 2010; Grupp, 2015) e projeto "Documentação de Narrativas e Elaboração de Dicionário Canela" (PDN), nos seis conjuntos de traços semânticos por postulados por Mithun (1991). A lista completa de verbos considerados neste artigo pode ser consultada em Barros (2019).

\subsection{Traços semânticos de Intransitivos ( $\mathrm{Sa}$ )}

Separamos ao todo 136 verbos intransitivos que possuem argumentos do tipo Sa. A maioria dos verbos intransitivos presentes no corpus (81 verbos Sa) se encaixam no conjunto 1 de traços [+evento, +P/E/I, +controle]. Abaixo alguns exemplos de verbos que fazem parte desse conjunto:

\begin{tabular}{|c|c|c|}
\hline $\begin{array}{c}\text { acjê/ihncjêj }{ }^{4} \\
\text { "entrar (muitas coisas)" }\end{array}$ & $\begin{array}{l}\text { ahho/ihpihho } \\
\text { "misturar, juntar" }\end{array}$ & $\begin{array}{l}\text { ahte/hàhhêc } \\
\text { 'balançar a } \\
\text { cabeça/sim" }\end{array}$ \\
\hline $\begin{array}{l}\text { ahcahhõ/hàhcahhnõn } \\
\text { "queixar-se de" }\end{array}$ & $\begin{array}{l}\text { ahhy/hàhhyr } \\
\text { "dividir" }\end{array}$ & $\begin{array}{l}\text { ahtêp/hàhtêp } \\
\text { "aproximar-se" }\end{array}$ \\
\hline $\begin{array}{l}\text { ahcukê/hàhcukên } \\
\text { "encher a boca" }\end{array}$ & $\begin{array}{l}\text { ahkĩj/hàhkĩj } \\
\text { "roubar" }\end{array}$ & $\begin{array}{l}\text { ahwỳ/hàhwỳr } \\
\text { "suplicar, mendigar, } \\
\text { chamar, pedir" }\end{array}$ \\
\hline $\begin{array}{l}\text { ahcukre/hàhcukren } \\
\text { "correr (com tora)" }\end{array}$ & $\begin{array}{l}\text { ahkõpĩ/hàhkôpir } \\
\text { "verificar/analisar" }\end{array}$ & $\begin{array}{l}\text { ajcacà/ipicacà } \\
\text { "dançar" }\end{array}$ \\
\hline $\begin{array}{l}\text { ahcukij/hàhcukjêr } \\
\text { "procurar, buscar" }\end{array}$ & $\begin{array}{l}\text { ahpro/ipipror } \\
\text { "pôr lado a lado" }\end{array}$ & $\begin{array}{l}\text { ajcacwa/ipicacwỳr } \\
\text { "unir, misturar" }\end{array}$ \\
\hline
\end{tabular}

\footnotetext{
${ }^{4}$ Deixamos o clítico de terceira pessoa ( $\varnothing$-/ih-/in-/im-/i-) nos verbos a fim de orientar o leitor acerca da divisão existente entre monovalentes distintos na terceira pessoa no tempo passado.
} 
No entanto, 25 verbos do grupo Sa não apresentam o traço [+controle] e fazem parte do segundo conjunto de traços semânticos: [+evento, +P/E/I, - controle]:

\begin{tabular}{|c|c|c|}
\hline acto/ipictor & ajcaprã/ipicaprãr & awpa/hũpar \\
\hline "perder-se" & “vazar” & “ouvir" \\
\hline acxa/ipxar & ajcrà/ipicràn & apêt/hàpêt "assustar- \\
\hline "rir" & "espalhar, transmitir" & se" \\
\hline ahcaprĩ/hàhcaprĩ & amrã/ihcwỳr & ihcaca \\
\hline "ter compaixão" & "chorar" & "respirar" \\
\hline ahpo/ipipo & ampra/ ipĩmprar & incacarẽ \\
\hline $\begin{array}{c}\text { "prender-se, coisas pertos que } \\
\text { se colam" }\end{array}$ & “acordar" & "suspirar" \\
\hline ahtĩ/hàhhĩc & amti/ ipĩmtir & ihcakô \\
\hline “espirrar” & "sonhar" & "soar" \\
\hline
\end{tabular}

Dez verbos intransitivos fazem parte do terceiro conjunto de traços semânticos [+evento, - P/E/I, - controle]:

(30)

\begin{tabular}{|c|c|}
\hline jaxwỳ & amcwa/hàmcwỳr \\
\hline "derramar" & "receber o que é seu" \\
\hline ahtõc/hàhtõtõc & apê/hàpêr \\
\hline "barulho" & "ventar" \\
\hline ajcajõc/ipicajõc & pehpec \\
\hline “envelhecer” & "pingar" \\
\hline
\end{tabular}




$\begin{array}{cc}\text { ajpiê/ajpiêr } & \text { cajcoc } \\ \text { "gotejar, pingar" } & \text { "boiar, flutuar" } \\ \text { ajxwỳ/ipijaxwỳr } & \text { ahtũm/hàhtũm } \\ \text { "gotejar, pingar" } & \text { "precisar esperar" }\end{array}$

Quatro verbos encontrados apresentam o conjunto 4 de traços [- evento, - P/E/I, + controle]:

$$
\begin{aligned}
& \text { ahcuprõ/hàhcuprõn } \\
& \text { "preparado para viagem" } \\
& \begin{array}{c}
\text { to ahtwỳ/hàhhuc/ ipinhuc } \\
\text { resto" ou permanecer a noite; deixar o }
\end{array} \\
& \text { ahtàt/hàhtàt/jàhtàt } \\
& \text { "alguém que respeita" } \\
& \text { krĩ }
\end{aligned}
$$

No conjunto 5 [- evento, - P/E/I, - controle - afetação], encontramos oito exemplos:

(32)

ahcucrà/hàhcucrà
"pintado com urucum"
$\begin{gathered}\text { ajrêt/ipjarêt } \\ \text { ahkêt/hàhkêt } \\ \text { "ser muito" }\end{gathered}$
"complicado, difícil de entender"
ajhôc/ipihôc
"pintado"
"indistintamente, igual"
ajpẽncajrẽn/jàhcajrẽn
"ser generoso"
al, raso, idêntico, paralelo"
cuhkrit
"ser sadio"


Encontramos quatro verbos intransitivos ( $\mathrm{Sa}$ ) no conjunto 6 de traços [- evento, - P/E/I, - controle e + afetação]:

$$
\begin{aligned}
& \text { ajpã/ipipã "bêbado, atordoado" } \\
& \text { aptõ/hàptõ "preocupar-se" } \\
& \text { ajcagãn/ipicagãn "despedaçado" }
\end{aligned}
$$

$\mathrm{Na}$ tabela abaixo podemos analisar comparativamente os verbos intransitivos ( $\mathrm{Sa}$ ) de acordo com o conjunto de traço semântico que codificam:

Quadro 4 - conjunto de traços semânticos dos verbos intransitivos

\begin{tabular}{|l|c|}
\hline \multicolumn{1}{|c|}{ Traços semânticos (Mithun, 1991) } & Número de verbos (Sa) \\
\hline 1. $[+$ +evento, $+\mathrm{P} / \mathrm{E} / \mathrm{I},+$ controle] & $81(61,3 \%)$ \\
\hline 2. $[+$ +evento, $+\mathrm{P} / \mathrm{E} / \mathrm{I}$, -controle] & $25(18,9 \%)$ \\
\hline 3. $[+$ +evento, $-\mathrm{P} / \mathrm{E} / \mathrm{I}$, -controle] & $10(7,57 \%)$ \\
\hline 4. $[$-evento, $+\mathrm{P} / \mathrm{E} / \mathrm{I},+$ controle] & $4(3,03 \%)$ \\
\hline 5. $[$-evento, $-\mathrm{P} / \mathrm{E} / \mathrm{I}$, -controle, -afetação] & $8(6,06 \%)$ \\
\hline 6. $[$-evento, $-\mathrm{P} / \mathrm{E} / \mathrm{I}$, -controle, + afetação] & $4(3,03 \%)$ \\
\hline
\end{tabular}

\subsection{Traços semânticos de descritivos (So)}

Separamos 180 verbos descritivos (com argumento So) nos mesmos conjuntos de traços e obtivemos resultados diferentes dos resultados obtidos com a separação de intransitivos (com argumento $\mathrm{Sa}$ ):

24 verbos descritivos possuem o conjunto de traços 1 [+evento, +P/E/I, +controle]:

cahàc

harĩhrĩ

huphê 


\begin{tabular}{|c|c|c|}
\hline "repreender" & "pular, dançar" & "pegar a moça e estuprá-la" \\
\hline cakôc & harô & ihcakwỳr \\
\hline "falar" & $\begin{array}{l}\text { "andar de gatinho, } \\
\text { baixado, tocado no chão", }\end{array}$ & $\begin{array}{l}\text { 'inseminar, } \\
\text { ter relações sexuais' }\end{array}$ \\
\hline carôt & hêj & ihcuhkwỳr \\
\hline "esforçar-se" & 'mentir' & 'andar, correr' \\
\hline cato/ cator & hikwa & ihcũmpej \\
\hline $\begin{array}{c}\text { "achar, encontrar, } \\
\text { chegar/sair" }\end{array}$ & "deitar-se" & $\begin{array}{c}\text { "voltar a sociedade depois de um } \\
\text { tempo" }\end{array}$ \\
\hline hàr/xàr & hitô & huphê \\
\hline "fritar, assar" & “juntar" & "pegar a moça e estuprá-la" \\
\hline
\end{tabular}

15 verbos que apresentam o conjunto de traços 2 [+evento, $+\mathrm{P} / \mathrm{E} / \mathrm{I}$, -controle] também pertencem à classe dos descritivos:

\begin{tabular}{|c|c|}
\hline ajhu & hipô \\
\hline "tropeçar" & "não ver, não perceber" \\
\hline
\end{tabular}

$\begin{array}{ccc}\begin{array}{c}\text { hàhcurê } \\ \text { "odiar" }\end{array} & \begin{array}{c}\text { hõjahĩ } \\ \text { "vomitar" } \\ \text { "coçar" }\end{array} \\ \begin{array}{c}\text { cacrõcrõc } \\ \text { "roncar" }\end{array} & \begin{array}{c}\text { ihkwỳr } \\ \text { "arrotar" }\end{array} \\ \text { catõc } & \text { "defecar" } \\ \text { "estourar" } & \text { "mancar" } & \text { hapactu }\end{array}$




$\begin{array}{cc}\text { (n)xô } & \text { rãn } \\ \text { "esvaziar" } & \text { "coxear" }\end{array}$

16 verbos apresentam o conjunto de traços 3 [+evento, -P/E/I, -controle]:

(36)

$\begin{array}{ccc}\begin{array}{c}\text { ahkrojkroj } \\ \text { "desfolhar" }\end{array} & \begin{array}{c}\text { ihcajcoc } \\ \text { "melhorar" }\end{array} & \begin{array}{c}\text { ihpỳpỳm } \\ \text { "nascer" }\end{array} \\ \text { hahhe } & \text { ihcukã } & \text { ihtotoc } \\ \text { "abrir, estender-se (planta)" } & \text { "agrolado (farinha), } \\ \text { fender-se em lascas" } & \\ \text { hàhtàt } & \text { ihhorhot } & \text { jamre } \\ \text { "abster-se, impedido" } & \text { "ferver" } & \text { "acabar" } \\ \text { hipêj } & \text { ihpêrpêt } & \text { ihpỳm } \\ \text { "acabar" } & \text { "esvoaçar, palpitar, } & \text { "cair" } \\ \text { vibrar" } & \text { "ferver, cozinhar" } \\ \text { hipy } & & \text { tyc } \\ \text { tempo marcado" } & & \end{array}$

Três verbos apresentam o conjunto de traços 4 [-evento, +P/E/I, +controle]:

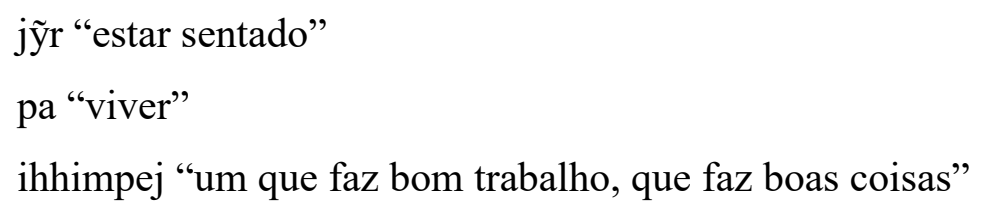

A grande maioria dos verbos descritivos (95 dos 180), entretanto, possuem os traços [-evento, -P/E/I, -controle, -afetação]: 


$\begin{array}{ccc}\text { akare } & \text { cajõc } & \text { caprec } \\ \text { "ser branco" } & \text { "ser curvado, torcido" } & \text { "ser vermelho" } \\ \text { amkrãhti } & \text { cakrã } & \text { caprỳ } \\ \text { "ser nublado" } & \text { "ser nublado" } & \text { "ser vazio" } \\ \text { apu ihkên } & \text { cakôni } & \text { carã } \\ \text { "ser devagar" } & \text { "ser primogênito" } & \text { "ser limpo" } \\ \text { cacrujre } & \text { capat /ipicapat } & \text { carĩ } \\ \text { "ser morno" } & \text { "delgado, magro" } & \text { "ser vazio (cabaça)" } \\ \text { cahàc } & \text { capẽn } & \text { catàt } \\ \text { "mal, feio" } & \text { pacífico" } & \end{array}$

27 verbos fazem parte do conjunto de traços 6 [-evento, -P/E/I, -controle, +afetação]:

(39)

akry

"ser frio"

$$
\text { hakry }
$$

"ser feliz"

hakrô

"estar de resguardo"

cacro

"ser quente"

catac

"ser zangado, furioso" "ser enfeitado"

hàprê/ jàprê

"ser feroz, bravo"

hitõt

“de má vontade,

preguiçoso"

hà

hõtxwa

hũpa

"ter medo"

irã

"ser sujo"

ihkro

"ter mal cheiro"

ihkro

"ser pintado"

ihcrôcrô 
O traço [afetação] não parece ser relevante para distinguir verbos intransitivos e descritivos em Canela, visto que, no conjunto de traços 5 e 6, só acontecem verbos descritivos.

Os descritivos, como podemos perceber, fazem parte dos seis conjuntos de traços, porém com uma grande maioria com os traços [-evento] e [-P/E/I]. O quadro 5 sistematiza os verbos descritivos (So) de acordo com o conjunto de traços semânticos que codificam:

Quadro 5 - conjunto de traços semânticos dos verbos descritivos

\begin{tabular}{|l|c|}
\hline \multicolumn{1}{|c|}{ Traços semânticos (Mithun, 1991) } & Número de verbos (So) \\
\hline 1. $[+$ +evento, +P/E/I, +controle] & $24(13,3 \%)$ \\
\hline 2. $[+$ +evento, +P/E/I, -controle] & $15(8,3 \%)$ \\
\hline 3. $[+$ evento, -P/E/I, -controle] & $16(8,8 \%)$ \\
\hline 4. $[$-evento, +P/E/I, +controle] & $3(1,66 \%)$ \\
\hline 5. $[$ - evento, - P/E/I, - controle, - afetação] & $95(52,7 \%)$ \\
\hline 6. $[$ - evento, - P/E/I, - controle, + afetação] & $27(15 \%)$ \\
\hline
\end{tabular}

\section{Considerações finais}

No início deste texto, relembramos que o Canela possui um padrão de alinhamento morfossintático de intransitividade cindida evidenciado por propriedades gramaticais como distintas séries pronominais.

Observamos no gráfico 1 que o número de verbos intransitivos é maior (conjunto 1 [+ evento, $+\mathrm{P} / \mathrm{E} / \mathrm{I}$ e + controle]), comparativamente, aos dos descritivos. A última classe, entretanto, é predominantemente formada por verbos com conjunto de traços 5 [- evento, $\mathrm{P} / \mathrm{E} / \mathrm{I}$ e - controle]: 


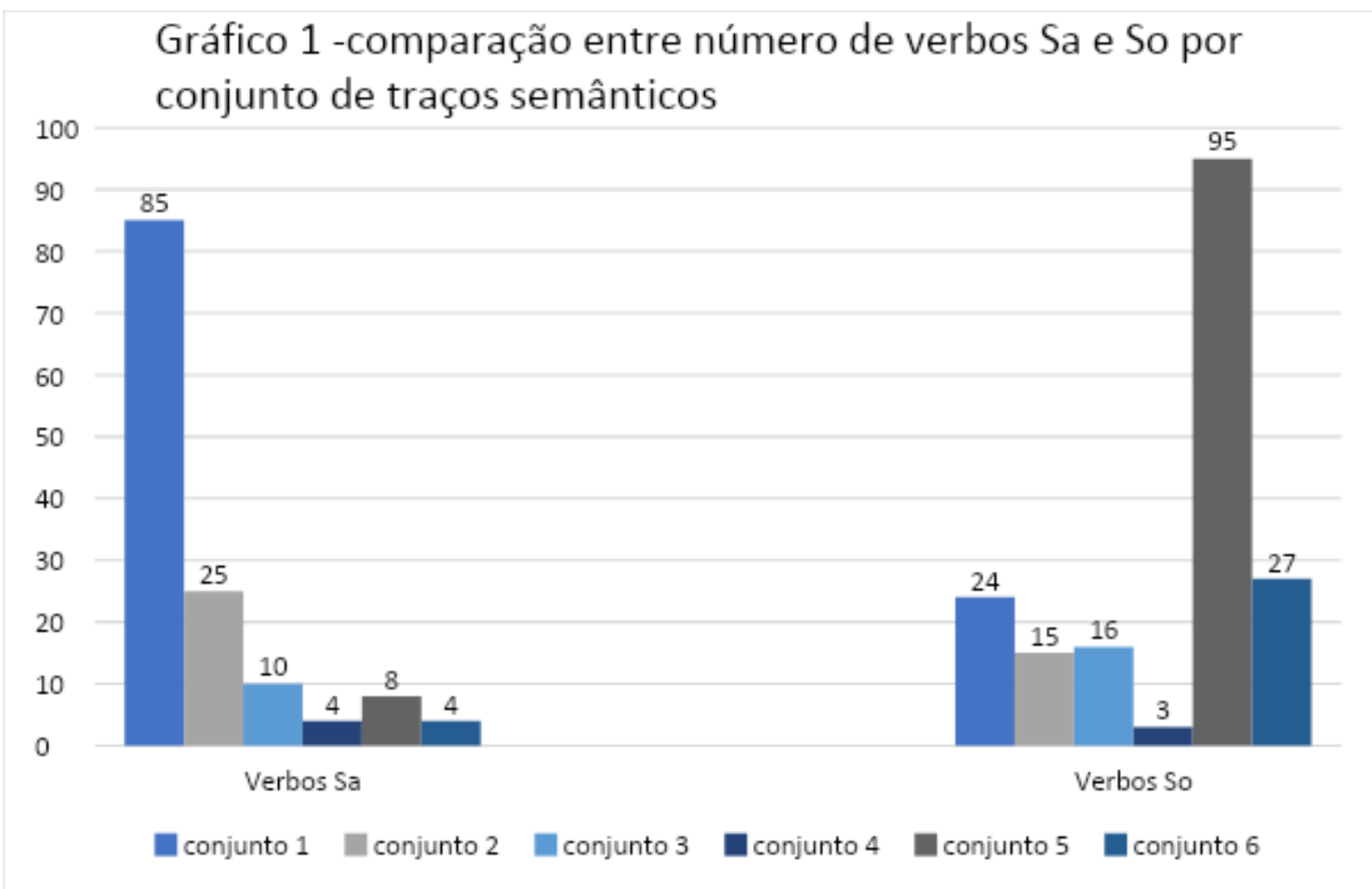

Com a aplicação da metodologia empregada por Mithun (1991, 2008), chegamos à seguinte conclusão: os traços [evento] e [P/E/I] são definidores para o padrão. Isso se dá, pois os resultados encontrados de verbos descritivos mostram uma tendência da classe com um inventário cuja maioria denota significado [-evento] e $[-\mathrm{P} / \mathrm{E} / \mathrm{I}]$, enquanto verbos intransitivos possui inventário cuja maioria de verbos denota significado [+evento] e [+P/E/I].

Sobre as exceções ao padrão semântico para argumentos de verbos descritivos (So), lembramos que Mithun (1991, 2008) verificou que processos diacrônicos podem ser responsáveis pela interferência a um padrão semântico transparente em algumas línguas. Uma futura pesquisa com esse viés ainda é necessária para entender melhor ainda a cisão intransitiva no Canela.

\section{REFERÊNCIAS BIBLIOGRÁFICAS}

BARROS, Murilo da Silva. Intransitividade Cindida em Língua Jê Setentrionais. Dissertação (Mestrado em Linguística) - Universidade de Brasília, Brasília, 2019.

BICKEL, Balthasar. Grammatical relations typology. In: SONG, Jae Jung (org.). The Oxford Revista Moara, n. 58, jan-jul 2021 ISSN: 0104-0944 
Handbook of Language Typology. Oxford: Oxford University Press. 2011. p. 399-444.

CASTRO ALVES, Flávia de. Aspectos fonológicos do Apãniekrá (Jê). Dissertação (Mestrado) - Universidade de São Paulo, São Paulo, 1999.

O Timbira falado pelos Canela Apãniekrá: Uma contribuição aos estudos da morfossintaxe de uma língua Jê. Tese (Doutorado). Universidade Estadual de Campinas, São Paulo, 2004.

Evolution of Alignment in Timbira. International Journal of American Lingüistics, v. 76, 2020. p. 439-475.

Aumento de valência em Canela. In: QUEIXALÓS,

Francesc; TELLES, Stella; BRUNO, Ana Carla. Incremento de valencia en las lenguas amazónicas (Publicaciones del Instituto Caro y Cuervo - Serie Coediciones VI). 1ed. Bogotá: Instituto Caro \& Cuervo, 2014, p. 191-210.

CREISSELS, Denis. Remarks on split intransitivity and fluid intransitivity. Empirical Issues in Syntax and Semantics 7 O. Bonami \& P. Cabredo Hofherr (eds.), 2008, p. 139-168. Disponível em: http://www. ssp. nrs.fr/eiss7. Acesso em: 06 de Junho de 2021.

DIXON, R. M. W. Ergativity. Cambridge: Cambridge University Press. 1994.

GRUPP, Bernard. Dicionário Canela. Brasil: MICEB. 2015.

KEREN, Rice. A Grammar of Slave. Berlin: Mouton de Gruyter. 1989.

KLIMOV, G. A. On the character of languages of active typology. Linguistics 131. 1974, p. $11-25$.

MEIRA, Sérgio. The accidental intransitive split in the Cariban family. Reconstructing Grammar: Comparative Linguistics and Grammaticalization Theory, ed. Spike Gildea. Amsterdam and Philadelphia: John Benjamins. 2000, p. 201-30.

MITHUN, Marianne. Active/agentive case-marking and its motivations. Language 67, 1991, p. $510-46$.

The emergence of agentive systems. The Typology of Semantic Alignment Systems. Mark Donohue and Soeren Wichmann, eds. Oxford University Press. 2008, p. 297-333. 
OLIVEIRA, Christiane C. The Language of the Apinajé people of central Brazil. $\mathrm{PhD}$, University of Oregon. 2005.

PERLMUTTER, D. M. Impersonal passives and the unaccusative hypothesis, Proceedings of the 4th Annual Meeting of the Berkeley Linguistics Society, 1978, p. 157 - 89.

POPJES, J.; J. Tentative phonemic statement of Canela. Summer Institute of Linguistics. 1971.

Canela-Krahô. In: DERBYSHIRE, D. C.; PULLUM, G. K. (eds). Handbook of Amazonian Languages, v. 1. Berlin/New York/Amsterdam: Mouton de Gruyter. 1986.

SESI/SENAI. Relatório de Gestão 2012 / elaborado pela Coordenação Geral de Planejamento e Orçamento CGPO/SESAI. Brasília: Ministério da Saúde: Secretaria Especial de Saúde Indígena, 2013. Disponível em: https://portalarquivos.saude.gov.br/images/pdf/2014/abril/22/relatorio-gestao-sesai-2012/. 